Document downloaded from:

http://hdl.handle.net/10251/102329

This paper must be cited as:

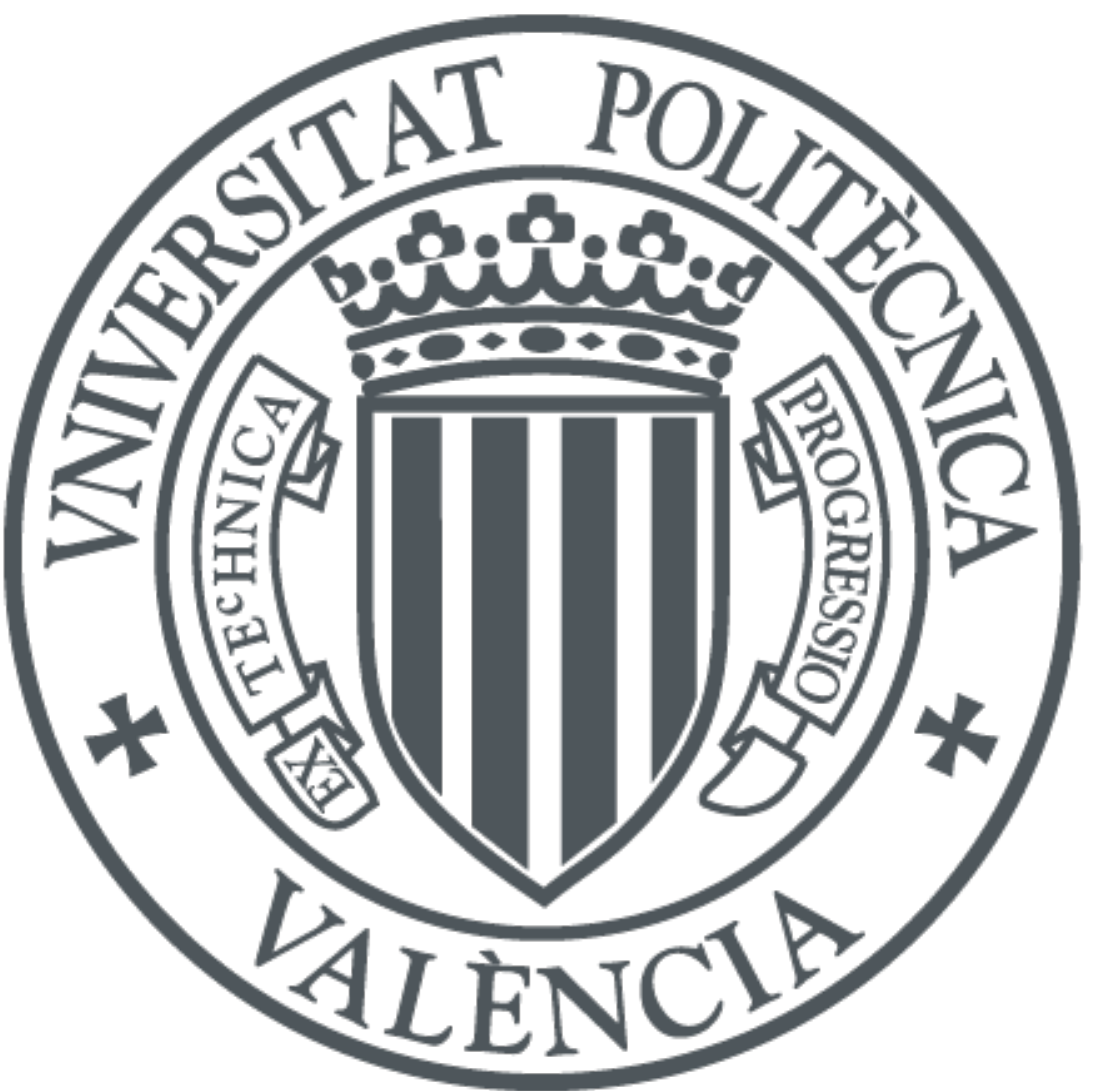

The final publication is available at

https://doi.org/10.1039/c6cc08175d

Copyright The Royal Society of Chemistry

Additional Information 


\title{
Photocages for protection and controlled release of bioactive compounds
}

\author{
I. Aparici-Espert, M. C. Cuquerella, C. Paris, V. Lhiaubet-Vallet*, M. A. Miranda* \\ Instituto Universitario Mixto de Tecnología Química (UPV-CSIC), Universitat Politécnica de \\ Valéncia, Consejo Superior de Investigaciones Científicas, Avda de los Naranjos s/n, 46022 \\ Valencia, Spain.E-mail: Ivirgini@itq.upv.es, mmiranda@qim.upv.es
}

\begin{abstract}
Using a sunscreen-based photocage, we have demonstrated that it is possible to prevent photodegradation of a bioactive compound and to achieve its controlled photorelease. The concept has been proven linking avobenzone, one of the most important UVA blockers, to ketoprofen, which is a representative example of a photosensitive drug.
\end{abstract}

\section{Results and Discussion}

A number of bioactive compounds are used under conditions that involve their exposure to sunlight. This may result in progressive photodegradation, leading to loss of activity and/or the appearance of undesired photoproducts. ${ }^{1,2}$ In this context, topical drugs are now in widespread use to treat illnesses as diverse as bacterial or fungal infections, allergic rash, musculoskeletal trauma, etc. The fact that the drug is applied directly to the affected area allows concentrating its effects where needed. As a consequence, for an almost comparable effectiveness, local application shows a better safety profile than oral medication as it minimizes the spread of the active ingredients through the bloodstream to other parts of the body, thus reducing the risk of side effects such as gastric disturbances, generally associated with systemic delivery. ${ }^{3}$ However, the use of topical drugs is not innocuous and also presents drawbacks, the most important being related to the instability of some active constituents toward solar radiation. Sunlight exposure leads not only to degradation of the drug, thus decreasing its pharmacological effect, but also to the occurrence of chemical photosensitivity. ${ }^{4,5}$ This originates cutaneous side reactions such as phototoxicity or photoallergy, which typically appear as an exaggerated sunburn but they can also provoke severe and/or persistent reactions. ${ }^{4,5}$

In this context, topical pain relievers such as non-steroidal anti-inflammatory drugs (NSAIDs) are available in most of the example of this family is ketoprofen (KP, Scheme 1) that is responsible for pronounced cutaneous photosensitization. ${ }^{6-10}$ Nowadays, the 
occurrence of severe side effects of drugs is a central public health problem that needs for innovative therapeutic approaches. Hence, specific measures have been taken for establishing their conditions of use, and explicit warnings on sun exposure and persistent photosensitivity are now given in the medication leaflets recommending, for instance, sun protection. ${ }^{11}$

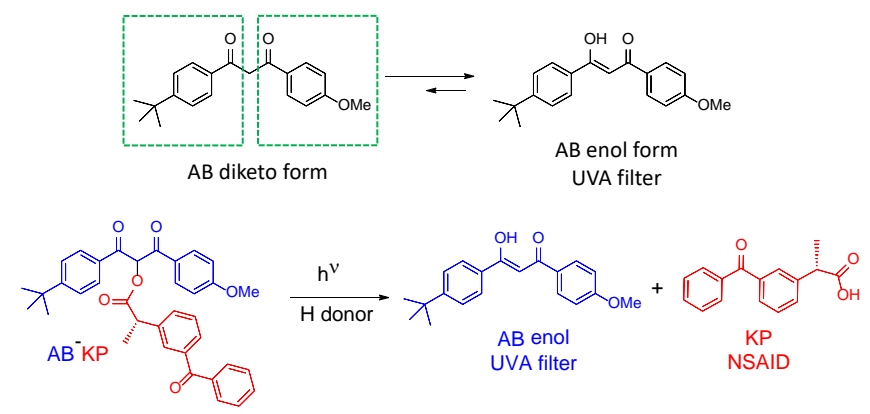

Scheme 1. Tautomeric equilibrium of $A B$. Structure of $A B-K P$ and photorelease of the latent $A B$ and $K P$.

It is well established that the in vivo photosensitizing properties of KP are linked to its reactivity in the UVA region of sunlight. Actually, the UV-Vis absorption spectrum of this drug exhibits two peaks, ie. an intense $\pi \pi^{*}$ absorption centered in the UVC at $254 \mathrm{~nm}$ and a weaker UVA band of $\mathrm{n} \pi^{*}$ nature at ca. $330 \mathrm{~nm}$ (Figure 1 and S1). ${ }^{6,8,12} \mathrm{In}$ this context, the development of sunscreen-based photocages (equivalent to covalently linked prodrug/pro-filter systems) could be considered a clever solution. This concept makes use of light-sensitive chemical moieties (photoremovable protecting groups, PPGs) to allow controlled and simultaneous release of the masked drug and the solar filter upon irradiation. This would be clearly advantageous over the mere mixture because it allows a controlled release of the two components. ${ }^{13}$ Photocages have become very popular because they provide spatial and temporal control over the activation of molecules triggered by light ${ }^{14-17}$ and have previously been employed for biological applications, ${ }^{15-19}$ such as photocaged nucleotides, ${ }^{20,} 21$ 20, 21 proteins, ${ }^{22-25}$ ions, ${ }^{26,}{ }^{27}$ neurotransmitters, ${ }^{28}$ pharmaceuticals, ${ }^{29-32}$ fluorescent dyes, ${ }^{32-34}$ or small molecules ${ }^{34-37}$. Interestingly, avobenzone ( $A B, 4$-tert-butyl-4'-methoxydibenzoylmethane), which is one of the most important and representative UVA blockers present in commercial sunscreens and cosmetic formulations, contains two phenacyl moieties that could in principle work as PPGs to release carboxylic acids (in green, Scheme 1). ${ }^{14-17}$ Being a dibenzoylmethane derivative, $A B$ suffers a keto-enol equilibrium, and the main enol tautomer is responsible for the large UVA absorption. ${ }^{38,39}$ Therefore, the phenacyl structure of AB diketo form could be used as a PPG of the KP carboxylic acid function as shown for compound AB-KP 
in Scheme 1. This design should result in a remarkable combination capable to provide a phototriggered slow delivery of the drug together with that of its UVA protective shield. Thus, KP photoreactivity should be inhibited and the risk of adverse skin reactions minimized, as the $A B$ absorption at ca. $350 \mathrm{~nm}$ is more than 200 times higher than that of KP (Figure S1).

Here, we report on the synthesis and photochemical evaluation of this photoactivatable dyad (AB-KP, Scheme 1). The synthesis of AB-KP was performed straightforward. First, $A B$ was brominated at the $\alpha$ position of the carbonyl groups by using $\mathrm{N}$-bromosuccinimide under solvent free conditions; then, the resulting intermediate was reacted with the $(S)$-ketoprofen cesium salt to afford a diastereoisomeric mixture of the desired $A B-K P$, which was found to be almost exclusively in the diketo form. Full NMR and HRMS characterization is given in the Supplementary Information. The uncaging process was performed without separating the $A B-K P$ diastereoisomers, because the new chiral carbon located on the $A B$ moiety should be lost during the photochemical release, while the pharmacologically active $(S)$ configuration of KP would be preserved.

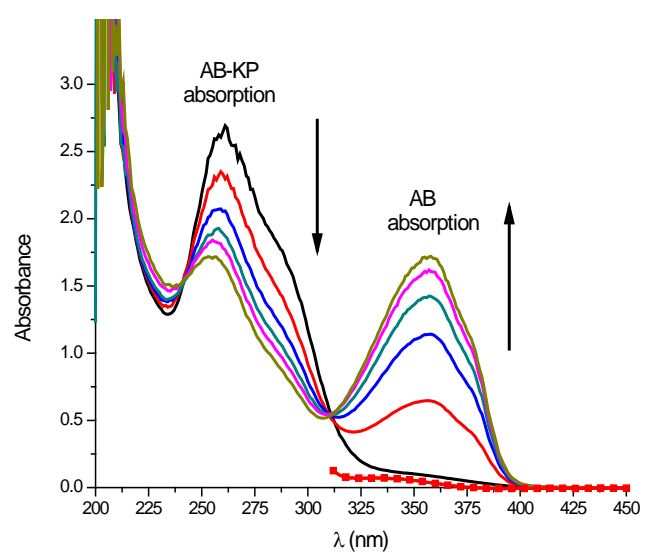

Figure 1. SSL-irradiation (from 0 to $30 \mathrm{~min}$ ) of $9 \times 10^{-5} \mathrm{M} \mathrm{AB-KP}$ in deaerated ethanol followed by UV absorption. Red dots shows the absorption of $7 \times 10^{-4} \mathrm{M} \mathrm{KP}$ in EtOH.

The pro-drug/pro-filter concept was easily checked by UV-Vis absorption spectroscopy monitoring the appearance of the characteristic UVA band of the enolic $A B$, centered at $355 \mathrm{~nm}$, upon irradiation as diagnostic for the release process (Figure 1). ${ }^{38,39}$ A nitrogen flushed solution of $A B-K P\left(9 \times 10^{-5} \mathrm{M}\right)$ in ethanol, selected as solvent for its hydrogen donor capability, was irradiated with simulated sunlight (SSL) provided by the filtered emission of a Xenon arc lamp. 
As observed in Figure 1, the diketonic AB-KP band decreased with irradiation time concomitantly with the increase of the $A B$ band, supporting formation of the enol tautomer of the filter.

Due to the close absorption maxima of $\mathrm{KP}^{12}$ and $\mathrm{AB}-\mathrm{KP}$ and the comparatively low molar absorption coefficient of KP at this wavelength, an accurate determination of the released drug required HPLC analysis, which was also achieved in a deaerated ethanol solution of $\mathrm{AB}-\mathrm{KP}$ at higher concentration $\left(1.1 \times 10^{-3} \mathrm{M}\right)$. Quantitation of the photoproducts was done by comparison with authentic samples of KP and AB. The HPLC traces revealed that the starting AB-KP peak disappeared over time giving actually rise to $K P$ and $A B$ (see Figure $S 2$ of Supplementary Information). The time course of the process is shown in Figure 2. After $15 \mathrm{~min}, 30 \%$ of the initial AB-KP had reacted, while after $2 \mathrm{~h}$ $A B-K P$ was almost totally consumed. Interestingly, under the same experimental conditions KP was completely photolyzed in less than $30 \mathrm{~min}$, clearly demonstrating the protecting role of the released $A B$ filter (Figure S3, Supplementary Information). Irradiation of an aerated ethanol solution under the same experimental conditions did not lead to formation of AB (Figure S4, Supplementary Information), in agreement with the involvement of a triplet excited state as intermediate. ${ }^{40}$

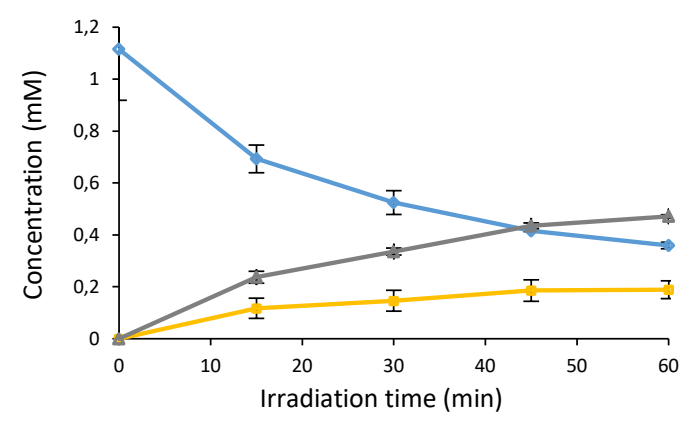

Figure 2. Time-course of the photorelease of $K P$ (orange line) and $A B$ (grey line) through simulated sunlight irradiation of a nitrogen flushed solution of $A B-K P$ (blue line, $1.1 \times 10^{-3} \mathrm{M}$ ) in ethanol. 


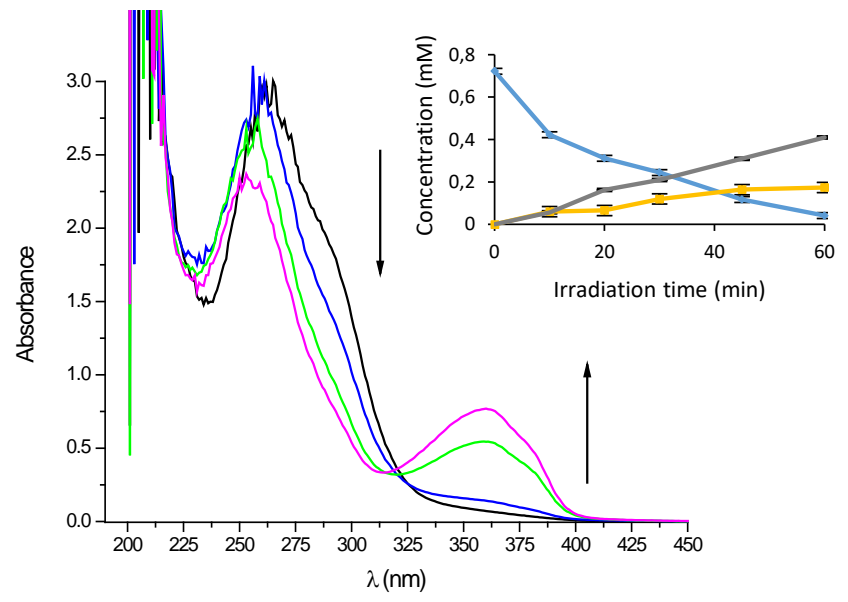

Figure 3. UV absorption changes for $A B-K P\left(9 \times 10^{-5} \mathrm{M}\right)$ in aerated propylene glycol under SSL (from 0 to 35 min). Inset: HPLC analysis for AB-KP $\left(7 \times 10^{-4} \mathrm{M}\right)$.

To go a step further and simulate the more viscous formulation compositions of topical creams, the photorelease was studied under air using propylene glycol as matrix. This way, the medium still presents hydrogen donor capability, but its lower diffusioncontrolled rate constant should disfavor the deactivation of excited states by oxygen. As shown in Figure 3, the $A B$ band appeared as a function of SSL irradiation time. This was confirmed by HPLC analysis were both $A B$ and KP peaks were detected.
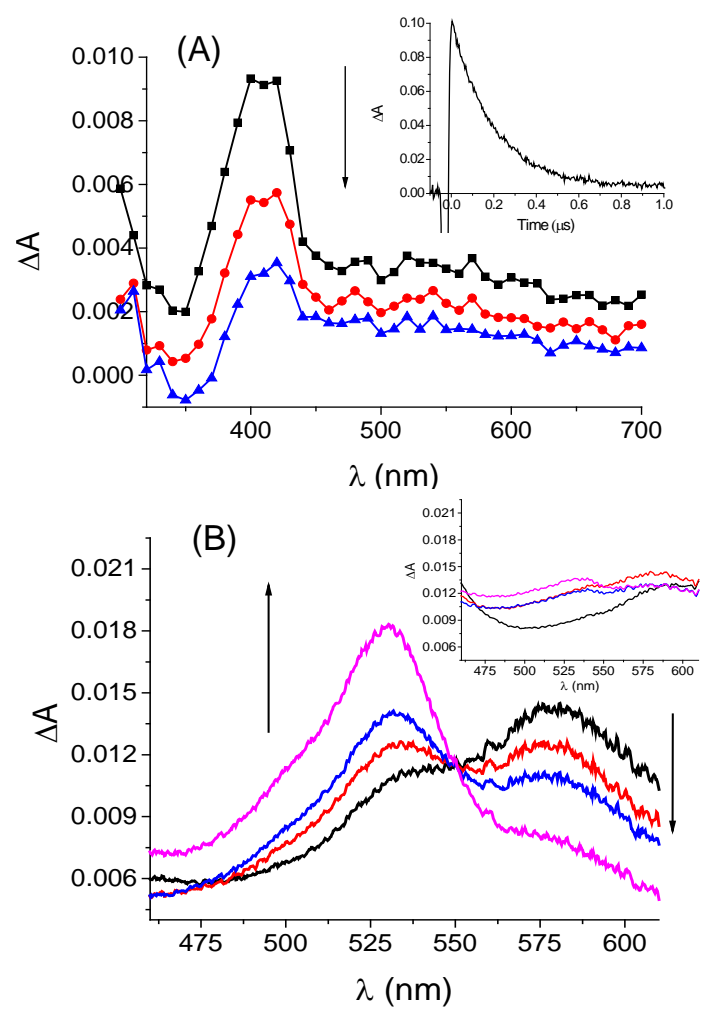

Figure 4. Transient absorption spectra of (A) AB-KP in ethanol under $\mathrm{N}_{2}$, from 0.05 to $0.3 \mu$ s after the $355 \mathrm{~nm}$ laser pulse, and (B) ketoprofen and $A B-K P$ (inset) from 3.1 to 15.8 ps after pump excitation. 
Finally, transient absorption spectroscopy was run to obtain direct information on the excited states involved in the photochemical process. Nanosecond laser flash photolysis experiments ( $\mathrm{Nd}: \mathrm{YAG}, 355 \mathrm{~nm}$ ) were performed on a nitrogen bubbled ethanol solution of $\mathrm{AB}-\mathrm{KP}\left(6.4 \times 10^{-4} \mathrm{M}\right)$. A transient absorption band centered at $400 \mathrm{~nm}$ appeared immediately after the pulse (Figure $4 \mathrm{~A}$ ) and decayed with a short lifetime of $0.2 \mu \mathrm{s}$ without leading to further detectable species. According to the literature data, this band was assigned to the triplet-triplet transition of the avobenzone-like diketo form. ${ }^{38}$ At this time window, the signal of the KP-like triplet excited state at ca. $525 \mathrm{~nm}^{12}$, 41 was not observed. This could mean that it is not formed during the process or that it is indeed formed, but it disappears at a shorter timescale. Hence, ultrafast transient absorption spectroscopy was used to analyze the sub-nanosecond processes. Under these conditions, for an ethanolic solution of KP alone, the characteristic singlet-singlet transition at $580 \mathrm{~nm}$ was observed; after few picoseconds intersystem crossing with formation of the triplet excited state absorbing at $525 \mathrm{~nm}$ was also noticed (Figure 4B) ${ }^{42}$. By contrast, the $525 \mathrm{~nm}$ species was hardly detected in the case of the AB-KP (Figure 4B, inset). This is in agreement with the accepted mechanism involved in the uncaging of compounds using phenacyl as PPG. ${ }^{40}$ After light absorption, the triplet excited state of the phenacyl chromophore abstracts hydrogen from the solvent, and subsequently releases KP. Once formed, $\mathrm{KP}$ is protected by the $\mathrm{AB}$ enolic form that absorbs much more efficiently UVA light, thus avoiding KP excitation.

\section{Conclusion}

In summary, the present work has demonstrated that it is possible to develop photocages for protection and controlled release of bioactive compounds. The concept has been proven using sunscreen-based photocages for topical drugs, which are associated with a double beneficial effect: controlled release of the photosensitive active principle upon light exposure coupled with its protection from photodegradation and photoreactivity by the solar filter effect. As both ingredients are registered compounds already in use, the pro-drug/pro-filter concept could in principle be brought to practical application in a time- and cost- efficient way.

\section{Acknowledgements}

Spanish Government (CTQ2015-70164-P, RIRAAF RETICS RD12/0013/0009, Severo Ochoa program/SEV-2012-0267 and BES-2013-066566), Generalitat Valenciana (Prometeo 
II/2013/005) and VLC/Campus Microcluster "Interacciones Luz-Fármaco en Sistemas Biológicos y Reacciones Adversas" are gratefully acknowledged.

\section{References}

1 H. H. Tonnesen, Photostability of Drugs and Drug Formulations (2nd Edition) CRC Press LLC, 2004.

2 M. R. Zaheer, A. Gupta, J. Iqbal, Q. Zia, A. Ahmad, Roohi, M. Owais, A. Hashlamon, S. H. M. Setapar, G. M. Ashraf and G. Aliev, Curr. Pharm. Des., 2016, 22, 768.

3 S. A. Klinge and G. A. Sawyer, Phys Sportsmed, 2013, 41, 64.

4 D. E. Moore, Drug Safety, 2002, 25, 345.

5 A. M. Drucker and C. F. Rosen, Drug Safety, 2011, 34, 821.

6 V. Lhiaubet-Vallet and M. A. Miranda, in CRC Handbook of Organic Photochemistry and Photobiology, $3^{\text {rd }}$ Ed, CRC Press, Boca Raton, 2012, vol. 2, ch. 66, pp. 1541.

7 H. Bagheri, V. Lhiaubet, J. L. Montastruc and N. Chouini-Lalanne, Drug Safety, 2000, 22, 339.

$8 \quad$ G. Cosa, Pure Appl. Chem. , 2004, 76, 263.

9 I. Karlsson, E. Persson, A. Ekebergh, J. Mårtensson and A. Börje, Chem. Res. Toxicol., 2014, 27, 1294.

10 Y. Seto, H. Ohtake, M. Kato and S. Onoue, J. Pharmacol. Exp. Ther., 2015, 354, 195.

11 https://www.gov.uk/drug-safety-update/topical-ketoprofen-reminder-on-risk-ofphoto-sensitivity-reactions).

12 F. Boscá and M. A. Miranda, J. Photochem. Photobiol. B: Biol., 1998, 43, 1.

13 K. Atarashi, M. Takano, S. Kato, H. Kuma, M. Nakanishi and Y. Tokura, J. Photochem. Photobiol. B: Biol., 2012, 113, 56.

14 T. Šolomek, J. Wirz and P. Klán, Acc. Chem. Res., 2015, 48, 3064.

15 D. D. Young and A. Deiters, Org. Biomol. Chem., 2007, 5, 999.

16 P. Klán, T. Šolomek, C. G. Bochet, A. Blanc, R. Givens, M. Rubina, V. Popik, A. Kostikov and J. Wirz, Chem. Rev., 2013, 113, 119.

17 H. Yu, J. Li, D. Wu, Z. Qiu and Y. Zhang, Chem. Soc. Rev., 2010, 39, 464.

18 A. Herrmann, Photochem. Photobiol. Sci., 2012, 11, 446.

19 C. Bao, L. Zhu, Q. Lin and H. Tian, Adv. Mater., 2015, 27, 1647.

20 M. C. Pirrung, Chem. Rev., 1997, 97, 473.

21 S. Panja, R. Paul, M. M. Greenberg and S. A. Woodson, Angew. Chem. Int. Ed., 2015, 54, 7281. 
22 J. Zhao, S. Lin, Y. Huang, J. Zhao and P. R. Chen, J. Am. Chem. Soc., 2013, 135, 7410.

23 C. W. Riggsbee and A. Deiters, Trends Biotechnol., 2010, 28, 468.

24 J. Luo, E. Arbely, J. Zhang, C. Chou, R. Uprety, J. W. Chin and A. Deiters, Chem. Commun., 2016, 52, 8529.

25 O. S. Walker, S. J. Elsässer, M. Mahesh, M. Bachman, S. Balasubramanian and J. W. Chin, J. Am. Chem. Soc., 2016, 138, 718.

26 T. M. Gomez and N. C. Spitzer, Nature, 1999, 397, 350.

27 H. W. Mbatia, H. M. Dhammika Bandara and S. C. Burdette, Chem. Commun., 2012, 48, 5331.

28 L. Sjulson and G. Miesenböck, Chem. Rev., 2008, 108, 1588.

29 R. Horbert, B. Pinchuk, P. Davies, D. Alessi and C. Peifer, ACS Chem. Biol., 2015, 10, 2099.

30 M. Lukeman and J. C. Scaiano, J. Am. Chem. Soc., 2005, 127, 7698.

31 G. Cosa, M. Lukeman and J. C. Scaiano, Acc. Chem. Res., 2009, 42, 599.

32 A. Jana, K. T. Nguyen, X. Li, P. Zhu, N. S. Tan, H. Ågren and Y. Zhao, ACS Nano, 2014, 8, 5939.

33 P. P. Goswami, A. Syed, C. L. Beck, T. R. Albright, K. M. Mahoney, R. Unash, E. A. Smith and A. H. Winter, J. Am. Chem. Soc., 2015, 137, 3783.

34 L. M. Heckman, J. B. Grimm, E. R. Schreiter, C. Kim, M. A. Verdecia, B. C. Shields and L. D. Lavis, Angew. Chem. Int. Ed., 2016, 55, 8363.

35 J. H. Kaplan, B. Forbush and J. F. Hoffman, Biochemistry, 1978, 17, 1929.

36 J. Engels and E. J. Schlaeger, J. Med. Chem., 1977, $20,907$.

37 D. Binder, C. Bier, A. Grünberger, D. Drobietz, J. Hage-Hülsmann, G. Wandrey, J. Büchs, D. Kohlheyer, A. Loeschcke, W. Wiechert, K.-E. Jaeger, J. Pietruszka and T. Drepper, ChemBioChem, 2016, 17, 296.

38 C. Paris, V. Lhiaubet-Vallet, O. Jiménez, C. Trullas and M. Á. Miranda, Photochem. Photobiol., 2009, 85, 178.

39 V. Lhiaubet-Vallet, M. Marin, O. Jimenez, O. Gorchs, C. Trullas and M. A. Miranda, Photochem. Photobiol. Sci., 2010, 9, 552.

40 J. Literák, A. Dostálová and P. Klán, J. Org. Chem., 2006, 71, 713.

41 V. Lhiaubet-Vallet, N. Belmadoui, M. J. Climent and M. A. Miranda, J. Phys. Chem. B, 2007, 111, 8277.

42 M.-D. Li, J. Ma, T. Su, M. Liu, L. Yu and D. L. Phillips, J. Phys. Chem. B, 2012, 116, 5882. 